\title{
A comparison of clinician and caregiver assessment of functioning in patients attending a child and adolescent mental health clinic in Nigeria
} \author{
O C Ogun, ${ }^{3} \mathrm{MBBS}, \mathrm{FWACP}$ \\ ${ }^{1}$ Department of Clinical Services, Neuropsychiatric Hospital, Aro Abeokuta, Nigeria \\ ${ }^{2}$ Department of Psychiatry, Ekiti State University Teaching Hospital, Ekiti, Nigeria \\ ${ }^{3}$ Clinical Services Department, Federal Neuropsychiatric Hospital, Yaba Lagos, Nigeria
}

A O Okewole, ${ }^{1}$ MBBS, FWACP; M U Dada, ${ }^{2}$ MB ChB, FWACP; M Bello-Mojeed, ${ }^{3}$ MBBS, FWACP;

Corresponding author: A O Okewole (niranokewole@gmail.com)

\begin{abstract}
Objective. To compare clinician and caregiver assessments of functioning and impairment among children attending a specialist mental health facility.

Methods. Caregivers of patients attending the Harvey Road Child and Adolescent Centre $(N=155)$ were consecutively recruited over a 1-month period. The caregivers were requested to fill in a sociodemographic questionnaire, the Columbia Impairment Scale (CIS), the 12-item version of the General Health Questionnaire (GHQ-12) and the Zarit Burden Interview. Scoring on the Children's Global Assessment Scale (CGAS) was done by clinicians.

Results. The mean (standard deviation (SD)) age of patients and caregivers was 12.3 (4.9) years and 41.5 (8.9), respectively. Mean (SD) scores on the CGAS and CIS were 55.3 (22.8) and 16.4 (14.3), respectively, while mean scores on the Zarit Burden Interview and the GHQ were 27.9 (17.2) and 2.5 (2.6), respectively. Poorer clinician-rated functioning was associated with lower educational level of the child, a main diagnosis other than seizure disorder, longer duration of illness, and presence of comorbidity. Worse caregiver rating of impairment was equally associated with lower child education, and main diagnosis other than seizure disorder. Both CGAS and CIS scores showed significant correlation with Zarit and GHQ scores. Finally, a significant correlation was found between CGAS and CIS scores $(r=-0.388, p<0.001)$.

Conclusion. Children attending specialist neuropsychiatric services have functional impairment which may be associated with lower child education, and which is linked with increased caregiver burden and psychiatric morbidity.
\end{abstract}

S Afr J Child Health 2016;10(1):8-11. DOI:10.7196/SAJCH.2016.v10i1.966

Previously, psychopathology has been viewed either from a categorical or a dimensional perspective. These have evolved into the multidimensional approach now favoured by the major classification systems in psychiatry. ${ }^{[1]}$ A key component of the multidimensional classification is the assessment of impairment, functioning and disability. Functional impairment, often a consequence of psychiatric symptoms, represents a reduced level of social, educational and/or occupational domains of life. ${ }^{[2]}$

It is argued that functional impairment should be viewed as a separate entity from the basic psychopathology ${ }^{[3]}$ The World Health Organization (WHO) in 2001 adopted an International Classification of Functioning, Disability and Health (ICF), which describes human functioning in terms of body structure, function, activities and participation. These are aspects of human function which influence, and are influenced by, state of health and environmental and personal factors. ${ }^{[4,5]}$ The ICF was adopted for use in children and adolescents in 2007..$^{[5,6]}$

Functioning and impairment have become central to our clinical decision-making. However, there is relatively little research on how well their impact can be measured. ${ }^{[2]}$ Rating scales for assessment of impairment are few in number and rarely used in clinical practice. ${ }^{[7]}$ One commonly used tool is the Children's Global Assessment Scale $(\mathrm{CGAS})^{[8-10]}$ which is a clinician-administered scale. In a society where expertise in child and adolescent mental health is rare, it is often necessary to rely on the caregiver for ratings of patient illness, response to treatment, and outcome. The caregiver, being more often in contact with the patient, can provide extremely valuable information on the patient's level of functioning. The extent to which the caregiver's report agrees with the clinician's rating is however often unclear.

In developing countries like Nigeria, there is a dearth of data on the level of functional impairment in children requiring services. ${ }^{[8]}$ This study therefore aimed to compare clinicians' and caregivers' assessments of functioning among children and adolescents attending a specialist psychiatric clinic.

\section{Methods}

A convenience sample of caregivers of children attending the Harvey Road Child and Adolescent Centre, Lagos $(N=155)$ were recruited over a 1-month period. This sample was taken from a pool of an average of 400 patients who visit the centre monthly: two clinics are run per week, with about 50 children seen at each clinic. The children seen at the clinic have a variety of diagnoses including autism spectrum disorders (ASD), attention deficit and hyperactivity disorder (ADHD), psychotic disorders, and intellectual disability. However, a large proportion of children seen have seizure disorder either as the main diagnosis or as a comorbidity with another disorder. Despite there being at least two paediatric neurology clinics in the Lagos metropolis, caregivers often prefer to use the Child and Adolescent Clinic because of the circumscribed nature of the service. To meet this demand, trainee psychiatrists are required to do neurology postings as part of their training, and in certain cases referrals are advised.

\section{Instruments}

A sociodemographic questionnaire was completed by the caregiver, which contained information about the child and caregiver. Some additional clinical details were obtained from the hospital records and filled in by the clinician.

The CGAS ${ }^{[11]}$ is a clinician rating of functioning in the child and adolescent population. It has been found to have good reliability and validity ${ }^{[12]}$ and has been used in a previous study among Nigerian children. ${ }^{[8]}$ The CGAS rates children on a scale of $1-100$, and is divided into ten categories. Higher scores on the CGAS are associated with better functioning. 
The Columbia Impairment Scale (CIS) ${ }^{[13]}$ is a 13-item self-rated questionnaire for assessing the caregiver's subjective impression of impairment in an ill child. Higher scores on the CIS are associated with poorer functioning. The items assess four key areas of functioning: interpersonal relations; broad psychopathological domains (e.g. anxiety, depression or behaviour problems); functioning in job or school; and use of leisure time. ${ }^{[1,13]}$ While it has proven validity in Caucasian populations, no available studies of its validity were found in this environment.

The burden of caring for the patients was assessed among caregivers using the Zarit Burden Interview. ${ }^{[14]}$ Psychiatric morbidity among the caregivers was assessed using the 12-item General Health Questionnaire (GHQ-12). ${ }^{[15]}$

The Lagos metropolis has residents from several of the ethnic groups which make up Nigeria. Translation of the study instruments into any particular dialect was not considered beneficial. The instruments were therefore administered in English.

\section{Procedure}

Subjects were recruited during routine clinic visits. Informed consent was duly sought, with verbal assent from the children where appropriate. Scoring on the CGAS was done by senior residents in psychiatry. The CGAS is part of routine patient assessment and no formal training was required. The caregivers were requested to fill in a sociodemographic questionnaire, the GHQ-12, the Zarit Burden interview and the CIS. Subjects who did not understand any particular item had such items explained to them by the investigators, and in some cases the items were read out to them.

\section{Ethical considerations}

Ethical approval was obtained from the Ethical Committee of the Federal Neuropsychiatric Hospital, Yaba. Informed consent was obtained from all subjects after the study protocol had been explained to them. Verbal assent was also obtained from children who were considered old enough.

\section{Statistical analysis}

Results were calculated as frequencies. Group comparisons were done using $\chi^{2}$ tests, correlations, independent sample $t$-tests and analysis of variance where appropriate. Tests were two-tailed, and the level of significance was set at $p<0.05$.

\section{Results}

A total of 155 caregivers of children with neuropsychiatric disorders participated in this study. The caregivers' ages ranged from 19 to 65 years, mean (standard deviation (SD)) age being 41.5 (8.9) years. The mean age of the children was 12.3 (4.98) years. Other sociodemographic and clinical variables of the children and their caregivers are presented in Table 1. Among the children, there was a slight male predominance, and more than half were in primary school or at a lower level (nursery school, kindergarten, or no formal education). Nearly half had been ill for more than 5 years, and in over half the main diagnosis was seizure disorder, while more than a third had a comorbid condition. The majority of the caregivers were female ( $71 \%$ being mothers), employed, married and of the Christian religion.

The mean score on the CGAS completed by clinicians was 55.3 (22.8). The mean scores on the CIS, the Zarit Burden interview and the GHQ-12, which were completed by the caregivers, were 16.4 (14.3), 27.9 (17.2) and 2.5 (2.6), respectively. Table 2 presents the associations between CGAS and CIS scores, respectively with various patient and caregiver variables. Lower CGAS scores (implying poorer clinician-rated functioning) were associated with lower educational level of the child, a main diagnosis other than seizure disorder, longer duration of illness, and presence of comorbidity. Higher CIS scores (implying worse caregiver rating of impairment) were equally associated with lower child education, and main diagnosis other than seizure disorder. Mothers also rated the children worse than other caregivers. Both CGAS and CIS scores showed significant correlation with Zarit and GHQ scores. Finally, a significant correlation was found between CGAS and CIS scores $(r=-0.388, p<0.001)$.

\section{Discussion}

This study provides comparative information on functional impairment among children with neuropsychiatric disorders attending a specialist facility in Lagos, Nigeria. A significant correlation was found between caregiver-rated level of functioning and clinician-rated level of impairment in the children. Concurrent validity of the CGAS and CIS has been reported in a Caucasian sample ${ }^{[1]}$ and in Nigeria, between the CGAS and another caregiver-rated measure, the Child Behaviour Questionnaire. ${ }^{[8]}$

Factors such as duration of illness and presence of comorbidity were associated with the clinician's assessment of functioning but not with that of the caregivers. From a clinical standpoint, it appears intuitive that these factors will contribute to, and be indices of, the functional capacity of the child over time. Longer duration of illness and psychiatric diagnosis have been associated with linguistic impairment among children with epilepsy. ${ }^{[16]}$ According to Hamiwka and Wirrell, ${ }^{[17]}$ comorbid conditions in children with epilepsy include cognitive impairment and neuropsychiatric problems, which are often more disabling to the children than the seizures themselves, and are a source of increased stress and burden for families.
Table 1. Sociodemographic profile of children and their caregivers

\begin{tabular}{ll}
\hline Variable & $\boldsymbol{n}(\%)$ \\
\hline Child's gender & \\
Male & $82(52.9)$
\end{tabular}

Female

Child's level of education

Primary or lower

Vocational or special

Secondary

Unspecified

Duration of illness (years)

$<1$

$1-5$

$>5$

Unspecified

Main diagnosis

Seizure disorder

ADHD/ASD

Mood/psychotic disorders

Intellectual disability

Comorbidity

Present

Absent

Unspecified

Gender of caregiver

Female

Male

Relationship of caregiver to child

Mother

Father

Others

Caregiver's employment status

Employed

Unemployed

Unspecified

Caregiver's marital status

Married

Not married

Caregiver's religion

Christianity

Islam

Other/unspecified

However, in a study among children with temporal lobe epilepsy, Pereira and Valente ${ }^{[18]}$ found no association between global functioning (as rated by clinicians using the CGAS) and seizure variables such as duration 
Table 2. Associations of CGAS and CIS scores with various child and caregiver variables

\begin{tabular}{|c|c|c|c|c|}
\hline Variables & CGAS scores, mean (SD) & Association & CIS scores, mean (SD) & Association \\
\hline \multicolumn{5}{|l|}{ Patient variables } \\
\hline Age & $55.3(22.8)$ & $r=0.142, p=0.106$ & $16.4(14.3)$ & $r=-0.065, p=0.425$ \\
\hline \multicolumn{5}{|l|}{ Sex } \\
\hline Male & $52.9(22.6)$ & $t=-1.303, p=0.195$ & $16.9(15.9)$ & $t=0.360, p=0.719$ \\
\hline Female & $58.2(22.5)$ & & $16.0(11.7)$ & \\
\hline \multicolumn{5}{|l|}{ Level of education } \\
\hline Primary or lower & $54.1(21.8)$ & $F=12.276, p<0.001^{*}$ & $18.7(15.4)$ & $F=3.971, p=0.021^{*}$ \\
\hline Vocational or special & $40.2(17.5)$ & & $16.0(12.3)$ & \\
\hline Secondary & $68.9(20.1)$ & & $10.6(11.2)$ & \\
\hline \multicolumn{5}{|l|}{ Duration of illness (years) } \\
\hline$<1$ & $70.3(16.0)$ & $F=7.794, p=0.001^{*}$ & $12.0(11.9)$ & $F=1.014, p=0.365$ \\
\hline $1-5$ & $59.0(21.7)$ & & $17.4(15.6)$ & \\
\hline$>5$ & $48.4(21.9)$ & & $16.0(13.5)$ & \\
\hline \multicolumn{5}{|l|}{ Main diagnosis } \\
\hline Seizure disorder & $63.3(20.4)$ & $F=7.336, p<0.001^{\star}$ & $12.8(12.0)$ & $F=2.562, p=0.041^{\star}$ \\
\hline ADHD/ASD & $38.6(13.8)$ & & $19.6(14.1)$ & \\
\hline Psychotic disorders & $31.7(20.8)$ & & $13.0(15.1)$ & \\
\hline Intellectual disability & $51.4(22.9)$ & & $23.7(17.2)$ & \\
\hline \multicolumn{5}{|l|}{ Presence of comorbidity } \\
\hline Yes & $43.7(19.2)$ & $t=-6.164, p<0.001^{*}$ & $16.7(13.1)$ & $t=1.722, p=0.079$ \\
\hline No & $68.0(18.4)$ & & $12.0(12.9)$ & \\
\hline \multicolumn{5}{|l|}{ Presence of psychosis } \\
\hline Yes & $52.3(25.5)$ & $t=-0.594, p=0.554$ & $12.8(14.2)$ & $t=-0.731, p=0.466$ \\
\hline No & $56.0(21.4)$ & & $15.4(13.0)$ & \\
\hline \multicolumn{5}{|l|}{ Caregiver variables } \\
\hline Age & $55.3(22.8)$ & $r=-0.082, p=0.057$ & $16.4(14.3)$ & $r=0.057, p=0.517$ \\
\hline \multicolumn{5}{|l|}{ Sex } \\
\hline Male & $56.0(22.5)$ & $t=0.745, p=0.458$ & $15.7(14.4)$ & $t=-1.25, p=0.213$ \\
\hline Female & $52.3(24.4)$ & & $19.3(13.9)$ & \\
\hline \multicolumn{5}{|l|}{ Relationship to patient } \\
\hline Mother & $55.6(23.1)$ & $t=0.264, p=0.793$ & $20.7(14.9)$ & $t=-2.109, p=0.037^{\star}$ \\
\hline Other & $54.3(23.2)$ & & $15.0(13.9)$ & \\
\hline \multicolumn{5}{|l|}{ Employment status } \\
\hline Employed & $57.1(22.2)$ & $t=1.747, p=0.083$ & $16.4(14.3)$ & $t=-0.214, p=0.831$ \\
\hline Unemployed & $46.3(24.7)$ & & $17.1(14.8)$ & \\
\hline \multicolumn{5}{|l|}{ Marital status } \\
\hline Married & $55.7(22.8)$ & $t=1.461, p=0.146$ & $15.9(14.1)$ & $t=-0.836, p=0.405$ \\
\hline Not married & $49.2(22.6)$ & & $57.2(22.1)$ & \\
\hline \multicolumn{5}{|l|}{ Religion } \\
\hline Christianity & $57.2(22.1)$ & $t=0.637, p=0.525$ & $16.2(15.2)$ & $t=0.328, p=0.743$ \\
\hline Islam & $54.4(23.2)$ & & $17.1(12.1)$ & \\
\hline Zarit score & $55.3(22.8)$ & $r=-0.47, p<0.001^{*}$ & $16.4(14.3)$ & $r=0.550, p<0.001^{\star}$ \\
\hline GHQ score & $55.3(22.8)$ & $r=-0.237, p=0.006^{*}$ & $16.4(14.3)$ & $r=0.506, p<0.001^{*}$ \\
\hline *Significant. & & & & \\
\hline
\end{tabular}


of illness. Nevertheless, the fact that no significant association with these variables was found with the caregivers' assessment may be a limitation of the CIS as an instrument, rather than conclusive evidence that longer duration of illness and presence of comorbidity do not factor into a mother's assessment of the child's level of impairment.

For both clinicians and caregivers, a lower level of educational attainment was associated with poorer functional capacity. Functional impairment and poor educational outcomes have been reported in ADHD and autism, ${ }^{[19,20]}$ as well as in epilepsy. ${ }^{[21]}$ A search of the literature, however, yielded no study providing empirical justification for the agreement between clinicians and caregivers.

Further, for both clinicians and caregivers, seizure disorder was associated with relatively better functioning, possibly because in between seizure episodes most children are essentially normal, and in many cases seizure control is attainable. Disorders such as ADHD and intellectual disability, which run a stable course, take a persistent toll on the caregiver, and have been shown to be associated with more impairment. ${ }^{[8]}$ The agreement between clinicians and caregivers on the relative better functioning of children with epilepsy, however, requires further study.

Caregiver-rated level of functioning was significantly associated with the relationship with the child, with mothers likely to rate the child as more impaired. This may be because mothers have more contact time with the child, and the burden of caring for an ill child falls more often on the mother. ${ }^{[22]}$ Being a mother has been reported to be associated with more psychiatric morbidity among caregivers of children with epilepsy, ${ }^{[23]}$ and mothers of functionally impaired children are more likely to have mental ill health ${ }^{[8]}$ which has been postulated to influence their assessment of the child. ${ }^{[24]}$

Both the CGAS and the CIS showed a significant association with the burden experienced by the caregiver and the psychiatric morbidity experienced by the caregiver. Higher impairment, or poorer functioning, results in more requirements being made of the caregiver, with a consequent heavier burden and a greater likelihood of psychiatric morbidity in the caregiver. ${ }^{[25,26]}$

The study was limited in that for certain variables, incomplete information reduced the number of units available for analysis, in what was at best a modest sample size. Another limitation of the study, besides the absence of prior validation of the CIS, is the fact that raters on the CGAS were not blind to patient diagnosis. This has the possibility of introducing bias. Furthermore, although all raters had undergone similar residency training and their use of the CGAS could be considered equivalent, no objective assessment of inter-rater reliability was done. The study was also conducted in a single clinic population, limiting generalisability. Nevertheless, this study gives vital information from a less-researched child population.

Although this study was not designed as a validation study, the CIS appears to be a useful tool in the assessment of functional impairment in children and adolescents. Further studies will, however, need to be done to assess its psychometric properties. Studies will also need to utilise more robust tools such as the WHO Disability Assessment Schedule.

\section{Conclusion}

The study showed that children attending specialist neuropsychiatric services have notable levels of functional impairment which may be associated with lower child education and which are linked with increased caregiver burden and psychiatric morbidity. This highlights the clinical importance of routine assessment of functional impairment in children with neuropsychiatric disorders. An additional implication of this finding, in a resource-constrained setting, is that policy initiatives with creative strategies are required for a holistic approach to neuropsychiatric disorders. This has to be multisectoral, involving in particular educational and social welfare services. Mother-andchild healthcare platforms may also need to be integrated to ensure that the burden and morbidity associated with caring for children with neuropsychiatric disorders are not unattended.
Acknowledgement. This article was presented at the World Psychiatric Association Regional Conference, Abuja, Nigeria, 22 - 24 October 2009.

\section{References}

1. Steinhausen HC, Metzke CW. Global measures of impairment in children and adolescents: Results from a Swiss community survey. Aust N Z J Psychiatry 2001;35(3):282-286. [http://dx.doi.org/10.1046/j.1440-1614.2001.00901.x]

2. Stringaris A, Goodman R. The value of measuring impact alongside symptoms in children and adolescents: A longitudinal assessment in a community sample. J Abnorm Child Psychol 2003;41(7):1109-1120. [http://dx.doi.org/10.1007/ s10802-013-9744-x]

3. Sartorius N. Disability and mental illness are different entities and should be assessed separately. World Psychiatry 2009;8(2):86. [http://dx.doi. $\operatorname{org} / 10.1002 / j .2051-5545.2009 . t b 00220 . x]$

4. World Health Organization (WHO). International Classification of Functioning, Disability and Health (ICF). Geneva: WHO, 2001.

5. Faulks D, Norderyd J, Molina G, et al. Using the International Classification of Functioning, Disability and Health (ICF) to describe children referred to special care or paediatric dental services. PLoS ONE 2013;8(4):e61993. [http:// dx.doi.org/10.1371/journal.pone.0061993]

6. WHO. International Classification of Functioning, Disability and Health Children and Youth Version (ICF-CY). Geneva: WHO, 2007.

7. Skounti M, Bitzaraki A. The clinical impairment of children with attention deficit hyperactivity disorder: Problematic of diagnostic criteria. Psychiatriki 2011;22(2):158-163

8. Tunde-Ayinmode M, Adegunloye O, Ayinmode B, Abiodun O. Psychiatric disorders in children attending a Nigerian primary care unit: Functional impairment and risk factors. Child Adolesc Psychiatry Ment Health 2012;6(1):28. [http://dx.doi.org/ 10.1186/1753-2000-6-28]

9. Al-Ansari AM. Measurement of impairment among children with attention deficit hyperactivity disorder as part of evaluating treatment outcome. Sultan Qaboos Univ Med J 2013;13(2):296-300. [http://dx.doi. org/10.12816/0003237]

10. Wigman JTW, Devlin N, Kelleher I, et al. Psychotic symptoms, functioning and coping in adolescents with mental illness. BMC Psychiatry 2014;14:97. [http:// dx.doi.org/10.1186/1471-244X-14-97]

11. Schaffer D, Gould MS, Brasic J, et al. A Children's Global Assessment Scale (CGAS). Arch Gen Psychiatry 1983;40(11):1228-1231.

12. Rey JM, Starling J, Wever C, Dossetor DR, Plapp JM. Inter-rater reliability of global assessment of functioning in a clinical setting. J Child Psychol Psychiatry 1995;36(5):787-795. [http://dx.doi.org/10.1111/j.1469-7610.1995.tb01329.x]

13. Bird HR, Shaffer D, Fisher P, et al. The Columbia Impairment Scale (CIS): Pilot findings on a measure of global impairment for children and adolescents. Int J Methods Psychiatr Res 1993;3(3);167-176.

14. Zarit SH, Orr NK, Zarit JM.The Hidden Victims of Alzheimer's Disease: Families Under Stress. New York: New York University Press, 1985.

15. Goldberg D, Gater R, Sartorius N, et al. The validity of two versions of the General Health Questionnaire in the WHO study of mental illness in general health care. Psychol Med 1997;27(1):191-197.

16. Caplan R, Siddarth P, Vona P, et al. Language in pediatric epilepsy. Epilepsia 2009;50(11):2397-2407.

17. Hamiwka LD, Wirrell EC. Comorbidities in pediatric epilepsy: Beyond 'just' treating the seizures. J Clin Neurol 2009;24(6):734-742. [http://dx.doi. org/10.1177/0883073808329527]

18. Pereira A, Valente KD. Severity of depressive symptomatology and functional impairment in children and adolescents with temporal lobe epilepsy. Seizure 2013;22(9):708-712. [htpp://dx.doi.org/10.1016/j.seizure.2013.05.008]

19. Bussing BR, Mason DM, Bell L, Porter P, Garvan C. Adolescent outcomes of childhood attention deficit/hyperactivity disorder in a diverse community sample. J Am Acad Child Adolesc Psychiatry 2010;49(6):595-605. [http:// dx.doi.org/10.1016/j.jaac.2010.03.006]

20. Shattuck PT, Narendorf SC, Cooper B, Sterzing PR, Wagner W, Taylor JL. Postsecondary education and employment among youth with an autism spectrum disorder. Pediatrics 2012;129(6):1042-1049. [http://dx.doi. org/10.1542/peds.2011-2864]

21. Reilly C, Atkinson P, Das KB, et al Academic achievement in school aged children with active epilepsy: A population-based study. Epilepsia 2014;55(12):1910-1917. [http://dx.doi.org/10.1111/epi.12826]

22. Shore CP, Austin JK, Dunn DW. Maternal adaptation to a child's epilepsy. Epilepsy and Behaviour 2004;5(4):557-568. [http://dx.doi.org/10.1016/j. yebeh.2004.04.015]

23. Babalola EO, Adebowale TO, Onifade PO, Adelufosi AO. Prevalence and correlates of generalized anxiety disorder and depression among caregivers of children and adolescents with seizure disorders. J Behav Health 2014;3(2):122127. [http://dx.doi.org/10.5455/jbh.20140526121601]

24. Ordway MR. Depressed mothers as informants on child behavior: Methodological issues. Res Nurs Health 2011;34(6):520-532. [http://dx.doi. org/10.1002/nur.20463]

25. Okewole A, Dada MU, Ogun O, Bello-Mojeed M. Prevalence and correlates of psychiatric morbidity among caregivers of children and adolescents with neuropsychiatric disorders in Nigeria. Afr J Psychiatry 2011;14(4):306-309. [http://dx.doi.org/10.4314/ajpsy.v14i4.8]

26. Dada MU, Okewole NO, Ogun CO, Bello-Mojeed M. Factors associated with caregiver burden in a child and adolescent psychiatric facility in Lagos, Nigeria: A descriptive cross sectional study. BMC Pediatrics 2011;11(1):110. [http:// dx.doi.org/10.1186/1471-2431-11-110] 